\title{
The Keele curriculum model: A contemporary framework for designing an inter-professional technology enhanced nursing curriculum
}

\author{
Melanie Humphreys, Ian Wood, Carol D. Johnson, Pauline N. Walsh, Nicola Witton, Julie Green, \\ Sarah Corkhill \\ School of Nursing and Midwifery, Keele University, Clinical Education Centre, Stoke-on-Trent, UK \\ Email:m.humphreys@keele.ac.uk
}

Received 7 May 2013; revised 7 June 2013; accepted 10 July 2013

Copyright (C 2013 Melanie Humphreys et al. This is an open access article distributed under the Creative Commons Attribution License, which permits unrestricted use, distribution, and reproduction in any medium, provided the original work is properly cited.

\begin{abstract}
This paper outlines a curriculum model for contemporary programme design for the purpose of embedding educational innovation and technology within an inter-professional nursing curriculum. It has been developed from work within the School of Nursing and Midwifery at Keele University during the re-write of both the nursing and midwifery curriculum. The Nursing and Midwifery Council (NMC) require approval of all recordable programmes every five years and as such the school took this review as an opportunity to explore the curriculum model currently in use and develop an approach that would facilitate the professional requirements of the programme alongside the embedding of innovative learning and teaching methodologies. The model springs from extensive application of contemporary pedagogy underpinning adult learning, and forces consideration of cognitive alignment within a multi-modal delivery framework [1]. The model builds upon the early work of Fowler and Mayes [2] and later work of Bird [3] who explored the antecedents and underpinning theory for success within online learning experiences. This model has greater reach; having strategic fit for acontemporary "technology enhanced learning" application within further and higher education [4], whilst ensuring the achievement of given professional standards [5].
\end{abstract}

Keywords: Nursing; Curriculum; Inter-Professional; Technology-Enhanced; Model; Keele

\section{INTRODUCTION}

For many years, registered nurses have been required to practise in a constantly evolving health care system. Health care delivery in this context requires that the nurse of the future not only possesses the knowledge, attitudes and skills to practise safely and effectively in an evolving health care environment but, also has the academic and professional preparation that enables them to work competently within the culture in which they are likely to practice in the future [5]. Central to this is the need to ensure that the patient is at the centre of all professional practice whether this is direct patient care, coordinating care, managing care, leading teams, training and educating staff or supporting innovation and research. Within a context of health reform, nurses will be required to adapt to the major shift of care delivery from secondary care to primary care and community-based working, the management of chronic disease across the life span, the increasing specialisation of hospital-based care, and the expansion of roles in non-medical prescribing and nurse-led discharge. Consequently, it is incumbent upon the nurse education system to prepare undergraduates for a nursing career that involves selfdirected, autonomous, life-long learning whilst ensuring compassion remains at the heart of the system [6]. In response to these drivers, many nursing curricula have become content saturated and fail to meet the demand for an improved student experience, with more flexible and engaging modes of study, and heightened employability.

Within nursing education, academics often have both subject expertise and teacher status, as such have a strong allegiance to course design and curriculum development. Both content and pedagogy feature prominently, with key players driving for a synergistic relationship between the two; where cognitive alignment, through multi-modal delivery can be achieved. However, there are still critics who claim that nursing education contin- 
ues to be plagued with a saturation of content [7]. There are multitudes of contributing factors that underscore the complexity of the problem and validate the need for educational change at the level of curriculum design. Over the past five to ten years there have been huge developments in the way resources can be sourced, created and adapted to support learning within Higher Education Institutions (HEIs) [8], and nursing has attempted to keep pace with this [4]. However, there is some evidence of difficulties that academics experience in applying contemporary learning theories to course design [9], where the consistent application of pedagogy from first princeples can be lost [3].

The team at Keele agreed that, in striving towards a holistic approach within a curriculum framework that embraced innovative student learning where excellence in care delivery was a central tenet, there was a need to move away from heavy content delivery to more contemporary educational approaches $[4,6]$. The Keele curriculum model provides a template for course design in which the learner's cognitive and compassion attributes and the connectivity between the dynamics for learning are the most important design inputs. It is founded on sound theoretical principles but its strength lies in its simplicity and ease of use. Using this model gives the academic choices in the approach to delivery whilst enuring the key design criteria are not overlooked. The worked example offered within this paper will be nursing; however, the application to other healthcare fields may fit equally well.

\section{THEORETICAL UNDERPINNINGS TO THE KEELE CURRICULUM DESIGN MODEL}

The underpinning theoretical design was drawn initially from Bird's [3] 3 “C” model, where he develops an arument for three basic ingredients of an online learning experience, namely content or new concepts, knowledge construction and consolidation of learning through reflection. In the context of this model, social constructiveism was considered to be central to the model and the process of knowledge construction. The team at Keele developed this model further to move away from Bird's focus on online learning towards a more "technology enhanced” approach, and to capture the important elements of inter-professional collaboration, competence and compassion; essential features of a contemporary nursing curriculum [4]. Indeed, the Keele model was developed to a 6 " $C$ " model that encapsulates at its centre the "person-centred graduate nurse"; content, concept, construction, collaboration, consolidation and competence, which were developed in a dynamic 4 "layered", approach. The first two layers can be seen to be con- cerned with the "what" of the curriculum, whereas the outer two layers can be seen to be concerned with the "how" of the curriculum with focus on the student's experience.

\subsection{The Inherent Layers}

The Keele model places the person-centred graduate nurse at its core. As aspiring autonomous practitioners, student nurses need to be equipped to provide essential and complex care to a very high standard using the best available evidence and technology where appropriate [5]. A key activity was a number of workshops which focused on listening to users and carers, advocacy and support groups as well as clinical partners to ascertain their views on what made a good nurse. Thus the proramme team felt the primary aim of the programme was to produce a person centred graduate practitioner at the point of registration. Indeed since then both the Willis report [6] and the Francis report [10] have highlighted the importance of putting the patient central to all practice. These reports highlight the importance of the quailies of kindness, care and compassion. These qualities will be instrumental for our students when developing their confidence and competence as a professional nursing practitioner. We believe that valuing and respecting people's individuality is fundamental to person-centred care.

In Figure 1, the inner layer of the model focuses upon the content of the course, and can be changed to fit the different nature of the course under development. Within the nursing curriculum, the content was focused around the four key areas detailed by the NMC [5] and these were known as the core themes, they served to embrace the nurse of the future philosophy:

- Nursing Practice \& Decision Making

- Professional Values

- Communication and Interpersonal Skills

- Leadership, Management and Team-working.

The second layer of the model emphasises the concept approach to the content delivery (and is also concerned with the "what" of the curriculum). The three-year programme will have three year-long conceptual modules of study;

- Knowledge for Professional Nursing Practice (year one)

- Developing Professional Nursing Practice (year two)

- Transition to Professional Nursing Practice (year three)

Conceptual modules were developed to provide the organisational framework and structure for the curriculum content, in a deliberate attempt to foster a learnercentred approach over the three-year learning trajectory.

Today's student nurses live in an age of accelerated knowledge generation, changing health demographics, 


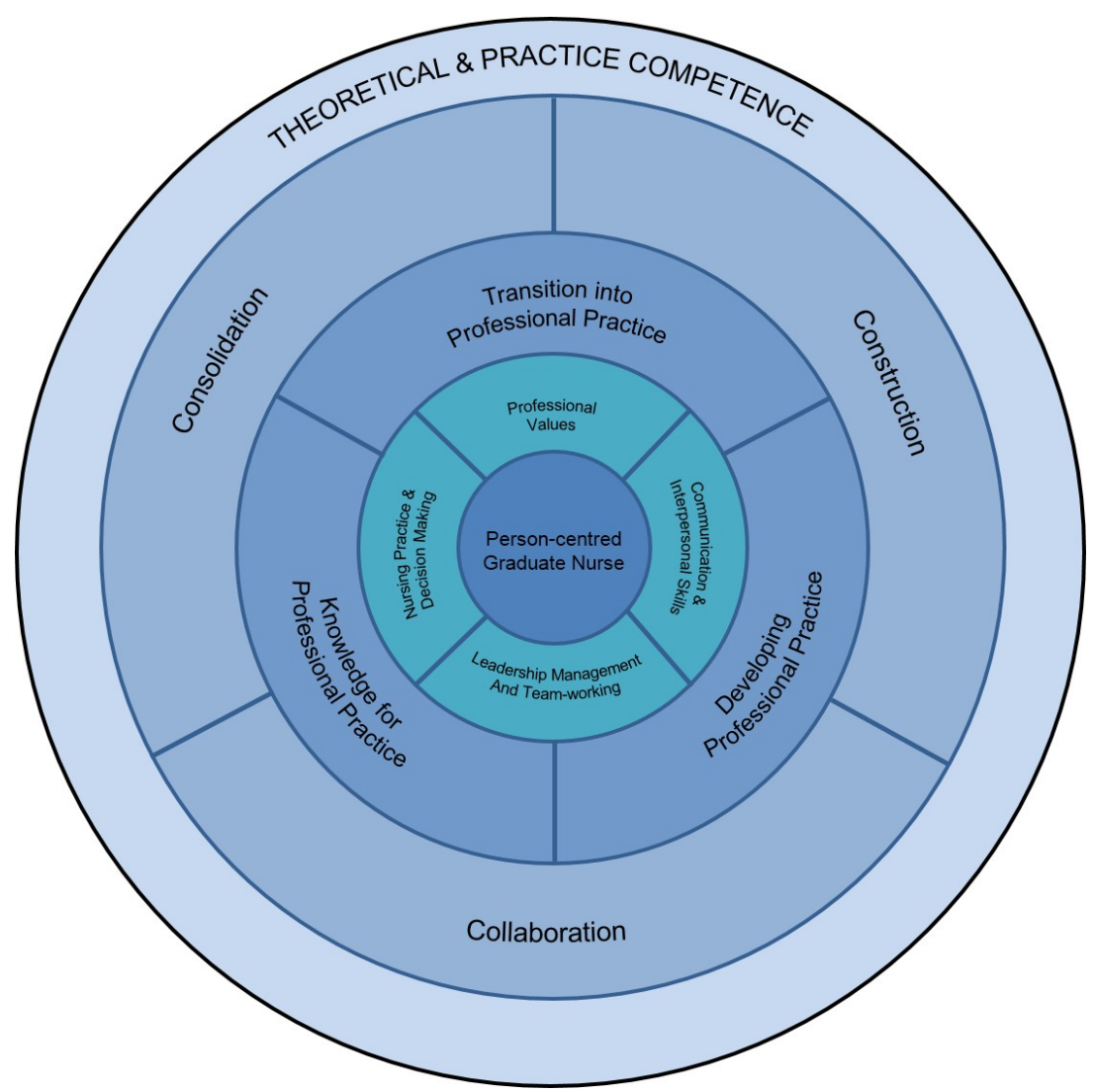

Figure 1. The Keele Curriculum Model: A contemporary framework for designing an inter-professional technology enhanced nursing curriculum.

and rapid technological advances. These exist both within the learning environment of the HEI, and also within the healthcare settings in which they must also learn and work. The learner-centred curriculum identifies student learning outcomes that are reflective of current nursing practice, uses authentic assessment, and provides learning experiences that move students toward the achievement of the intended curricular outcomes.

The third layer of the model (Figure 1) relates to the "how" of the curriculum and includes the dimensions of construction, collaboration, and consolidation. The theoretical consideration of these three fundamental aspects focuses on the notion of social constructivism and the process of knowledge construction.

\section{CONSTRUCTION}

The educational strategies adopted are informed by insights from social constructivist theory. The programme philosophy acknowledges that students are adults and bring to this educational experience a diversity of previus learning, experience and skills and that learning will be experienced and processed differently by individual students. The approach is learner-centred, acknowledging that learning is a social and active process [11,12]. Over the three-year programme, the intention is to facilitate the learner in constructing rather than merely acquiring knowledge. Students will construct knowledge by engaging in verbal and written reflection, through self-assessment in theory and practice, and by participating in practice-focussed problem-solving activities and simulated scenarios [13]. The construction of knowledge and skills will be further enhanced through inter-professional collaboration with other students and practitioners from a range of health care professions.

\section{COLLABORATION}

The constructivist theory serves to promote the need to work in collaboration with other professionals, and this is considered fundamental within the nursing curriculum $[5,10]$. Within the Keele design model, collaboration is seen as an integral and essential element of both the planning and delivery, with the focus on retaining current exemplars of good practice and developing new and innovative approaches. Collaboration is planned within three key areas: inter-professional education (IPE), involvement of clinical partners, and collaboration with service users and carers.

Within the Keele design model, IPE, learning (IPL) 
and working (IPW) are essential components to the oranisation and delivery of the programme and are based upon opportunities for collaboration with students from medicine, social work, pharmacy, physiotherapy, midwifery, operating department practice and the four fields of nursing. This will be maximised using a variety of methods and situational learning

Collaboration with clinical colleagues will provide support to ensure the maintenance of good quality mentorship whilst the students are in placements [14]. To further existing links with clinical staff their specialist expertise will be harnessed for the development of clinically relevant learning activities and the delivery of subject specific sessions [15].

Essential to the development of a learning-centred curriculum has been collaboration with service users, and their carers'. This will continue during curriculum implementation through their involvement in the development of learning resources and through the delivery of content, including involvement in the development of case scenarios; Objective Structured Clinical Examinations (OSCE) assessments; attendance at small group learning activitiesas "expert patients" thus enabling students to construct insights into conditions, their investigation and management and the experiences of care from the service users' perspectives $[16,17]$.

\section{CONSOLIDATION}

The final theoretical consideration within the third layer concerns consolidation of learning. This will be facilitated through reflection as its partwithin the educational process is well documented [18-20].

Consolidation is best achieved through dialogue [3]. There are many layers and levels within this process, and these include student-to-mentor, student-to-tutor. and peer-to-peer dialogues. For the duration of the programme, each student will converse with their personal tutor about their reflections on their development towards professional competence. Evidence of these conversations (and others) will be captured by the use and integration of an ePortfolio for each student that will develop over the three years of their programme. These will serve to facilitate the exploration of multiple perspectives and the exchange of experiences and ideas vital to the social construction of knowledge.

The fourth and final layer of the model relates to the acquisition of theoretical and practical competence-the "achievement" of the programme.

A central concept of learning-centred education is that teachers, mentors and students are all learners, working together to explore and develop students' competence, which works well in both an academic and practice setting and is typically constructivist in nature. There is

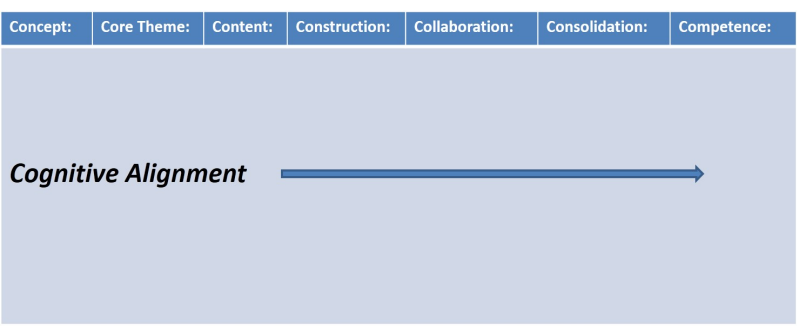

Figure 2. The Keele Curriculum Model: Cognitive alignment learning map.

some evidence that contemporary curriculum designs focusing upon concept-approaches and active learning strategies are having an impact upon enhanced compeence within practice [21,22,7].

The model and its underpinning pedagogy ensure consistent consideration and application of cognitive alignment within the multi-modal delivery framework [1]. Through the application of constructive alignment the teacher's role is to create a learning environment that supports the learning activities appropriate to achieving the desired learning outcomes. The key is that all components in the teaching system - the curriculum andits intended outcomes, the teaching methods used, the assessment tasks are aligned to each other. All are tuned to learning activities to create the curricular learning map (Figure 2).

\section{SUMMARY}

This paper has detailed a curriculum model for contemporary programme design for the purpose of embedding educational innovation and technology within an interprofessional nursing curriculum; the model can be seen to have clear alignment with current political and pedagogical themes. It offers an approach that is cognisant of the fundamental values contained within the recent reports from both Willis [6] and Francis [7] and serves to ensure that the essential requirements of the nurse for the future are at its core.

\section{REFERENCES}

[1] Biggs, J.B. (2003) Teaching for quality learning at university. Open University Press, Buckingham.

[2] Fowler, C. and Mayes, J. (2000) Learning relationships from theory to design. In: Squires, D., Conole G. and Jacobs, G., Eds., The Changing Face of Learning Technology, University of Wales Press, Cardiff, 39-50.

[3] Bird, L. (2007) The 3 “C” design model for networkedcollaborative e-learning: A tool fornovice designers. Innovations in Education and Teaching International, 44, 153167.

[4] Department of Health (2011) A framework for technology enhanced learning. The Stationery Office, London. 
[5] Nursing \& Midwifery Council (2010) Standards for pre-registration nursing education. NMC, London.

[6] Willis, P. (2012) Quality with compassion: The future of nurse education. Royal College of Nursing, London.

[7] Giddens, J. F. and Brady, D. P. (2007) Rescuing nursing education from content saturation: The case for a concept-based curriculum. Journal of Nursing Education, 46, 65-69.

[8] Littlejohn, A. and Pegler, C. (2007) Preparing for blended e-learning. Routledge, London.

[9] Bradley, C. and Oliver, M. (2002) Developing e-learning courses for work-based learning, Proceedings of the 11th International World Wide Web Conference, 7-11 May 2002, Honolulu. http://www2002.org/CDROM/alternate/703/index.html

[10] Francis, R. (2013) Report of the mid Staffordshire NHS foundation trust public inquiry. The Stationary Office, London.

[11] Loyens, S. M. M., Rikers, R. M. J. P. and Schmidt, H.G. (2009) Students' conceptions of constructivist learning in different programme years and different learning environments. British Journal of Educational Psychology, 79, 501-514. doi:10.1348/000709908X378117

[12] Kala, S., Isaramalai, S. and Pohtong, A. (2010) Electronic learning and constructivism: A model for nursing education. Nurse Education Today, 30, 61-66. doi:10.1016/j.nedt.2009.06.002

[13] Brandon, A. F. and All, A. C. (2010) Constructivism theory analysis and application to curricula. Nursing Educa- tion Perspectives, 31, 89-92

[14] Beskine, D. (2009) Mentoring students: Establishing effective working relationships. Nursing Standard, 23, 35-40.

[15] Pollard, K. (2009) Student engagement in inter-professional working in practice placement settings. Journal of Clinical Nursing, 18, 2846-2856. doi:10.1111/j.1365-2702.2008.02608.x

[16] Lathlean, J., Burgess, A. and Coldham, T. (2006) Experiences of service user and carer participation in health care education. Nurse Education Today, 26, 732-737. doi:10.1016/j.nedt.2006.07.017

[17] McGarry, J. and Thom, N. (2004) How users and carers view their involvement in nurse education. Nursing Times, 100, 36-39.

[18] Schön, D. (1983) The reflective practitioner. Temple Smith, London.

[19] Kolb, D. (1984) Experiential learning: Experience as a source of learning and development. Prentice Hall, Englewood Cliffs.

[20] Boud, D., Keogh, R. and Walker, D. (1985) Reflection: Turning experience into learning. Kogan, London.

[21] Cassidy, S. (2009) Interpretation of competence in student assessment. Nursing Standard, 23, 39-46.

[22] Wellard, S.J., Bethune, E. and Heggen, K. (2007) Assessment of learning in contemporary nurse education: Do we need standardised examination for nurse registration? Nurse Education Today, 27, 68-72. doi:10.1016/j.nedt.2006.04.002 